\title{
ADDENDUM
}

\section{Robust direct effect of carbon dioxide on tropical circulation and regional precipitation}

Sandrine Bony, Gilles Bellon, Daniel Klocke, Steven Sherwood, Solange Fermepin and Sébastien Denvil

Nature Geoscience 6, 447-451 (2013); published online 21 April 2013; addendum published after print 27 June 2014

In our Letter discussing the direct effect of rising carbon dioxide concentrations on tropical circulation and precipitation, we meant "global mean surface warming" in all instances where we referred to "global surface warming". Our findings are therefore consistent with a recent report (Chadwick, R. et al. Geophys. Res. Lett. 41, 610-615; 2014) that finds that changes in spatial patterns of surface temperature may arise quickly in response to the increased $\mathrm{CO}_{2}$ radiative forcing (for example, through sea surface temperature anomalies driven by the effect of $\mathrm{CO}_{2}$ on surface winds and land-sea contrasts), and may amplify the circulation and precipitation responses in some regions.

We would also like to re-emphasize that the significant impacts of increases in atmospheric $\mathrm{CO}_{2}$ concentrations reported in our study do not imply that the long-term rainfall change pattern resulting from $\mathrm{CO}_{2}$-driven warming and the initial change pattern driven by rising atmospheric $\mathrm{CO}_{2}$ levels will strongly resemble each other. This is because, in some regions, the slower changes in response to global-mean warming and increased water vapour are nearly opposite to those induced rapidly by rising $\mathrm{CO}_{2}$ levels, whereas in other regions this is not the case. 